tat preponderent tumorile la adolescentele cu vârsta cuprinsă între 15-17 ani (86,9\%). După locul de trai au prevalat tumorile la minorele din sectorul rural $65 \%$. Fibroadenomul intracanalicular a fost depistat histologic în 55 (56,7\%) din cazuri.

\section{Concluzii}

1. Tumorile glandelor mamare la minore reprezintă o problemă actuală atât din punct de vedere medical, cât și social.

2. În baza semnelor clinice, examinarea glandelor mamare cu prezența tumorii palpabile, investigațiilor necesare poate fi stabilit diagnosticul de tumoare a glandelor mamare, cu aprecierea ulterioară a metodei de tratament.

3. Pe parcursul anilor 2013-2020 s-au înregistrat $97(100 \%)$ cazuri de tumori ale glandelor ma-

\section{Bibliografie}

1. Breast cancer highlights from ASCO 2004 (conference report). Int J Fertil Womens Med. 2004; 49(5): 239-40.

2. Buţureanu Şt. Patologie ginecologică benignă. Ed. Institutul European, 2004. 42.

3. Chang D.S., McGrath M.H., Management of benign tumors of the adolescent breast, Plast Reconstr Surg. 2007 Jul; 120(1): 13e-19e.

4. Copeland, Larry J.: Textbook of Gynecology, W.B. Saunders Company, 1999.

5. De Vitta V., Hellman S., Rosenberg S.A. Principles and practice of oncology, Jones and Bartlett publishers, 2003.

6. Diaconu C., Chifu C., Iftime C., Iftime I., Miron L., Carasevici E., Ferariu D., Cobzeanu C., Crumpei F. Bilateral mare, cele mai răspândite fiind fibroadenoamele (44 $(45,2 \%)$ cazuri), urmate de tumori filoide (20 (20,3\%) cazuri). În $86,9 \%$ din cazuri erau minorele cu vârsta de 15-18 ani. Indicii confirmă influenţa estrogenică asupra apariției tumorilor mamare la adolescente, în special a fibroadenomului. După mediul de trai a dominat mediul rural (65\%), ce denotă faptul că la minorele din localitățile rurale nu se efectuează screening-ul tumorilor glandelor mamare, având acces mai limitat la specialiști pentru evaluare și diagnostic.

4. Pe parcursul anilor 2013-2020 s-au înregistrat 3 cazuri de cancer (vârsta 16-17 ani).

5. Tumorile la sân în rândul minorelor crește, ce argumentează adresarea precoce la medicul specialist. Sunt argumentate măsurile de monitorizare a adolescenților în școli și licee.

breast cancer $(B B C)$. Considerations on a series of 20 cases. Rev Med Chir Soc Med Nat Iasi. 2006; 110(4): 867-73.

7. Greydanus D.E., Parks D.S., Farrell E.G: Breast disorders in children and adolescents. Pediatric Clin North Am 1989; 36:601.

8. Mereuţă I., Cernat V., Vozian I. Tumorile la copii. Managementul clinic al cancerelor ereditare. Ch.: Tipogr. „Print-Caro”, 2012, 72 p.

9. Mereuță I., Gațcan S. Mastopatiile difuze. Ch.: Print-Caro, 2012. - 151 p.

10. Țîbîrnă Gh. Ghid clinic de Oncologie. Chişinău: Univers, 2003, 828 p.

11. Окулов А.Б., Адамян Л.В., Бровин Д.Н., Богданова Е.А. Молочные железы и их заболевания у детей. М.: МИА, 2010. 160 c.

CZU: 616.831-006-053.2

https://doi.org/10.52692/1857-0011.2021.2-70.14

\title{
THE MANAGEMENT OF BRAIN TUMORS AT CHILDREN Angela LEANC̆
}

Children Clinical Hospital „V. Ignatenco”, Chisinau, the Republic of Moldova e-mail: leanca.angela@mail.ru

\section{Summary.}

Background: Brain tumors are a severe form of pathologies, that are more common in children and it is associated with hydrocephali. The long term effects of central nervous system therapy for children with brain tumors have been the subject of research since the 1970. Many studies have demonstrated that children treated for brain tumors with surgery and standard radiation therapy have developed intellectual decline which is progressive over at least a decade.

Risk factors for the cognitive deterioration have been identified and include: perioperative complications, hydrocephalus, high radiation dose, large volume radiation, chemotherapy (especially methotrexate), vasculopaty and young age at the time of treatment.

The purpose of research: Study of surgical treatment applied to children with brain tumors hydrocephalus by implementing and perfecting the surgical treatment. 
Material and methods: We used data of 2018-2019 period, in the Children Clinical Hospital „V. Ignatenco”, of the Republic of Moldova, which shows the structure of morbidity through malign and benign tumors with associated hydrocephalus at prematures population.

Results: Since 2018-2019 were diagnosed 13 children. The average age was: 1 child(0,76\%) 0-1 years old, 5 children (38,46 \%) 2-5 years old, 2 children (15,38\%) 6-10 years old and 5 children (38,46\%)11-17 years old. From 13 children, 2 children $(15,38 \%)$ were inoperable. The incidence was 10 boys $(76,92 \%)$ and 3 girls $(23,07 \%)$. There were complications: malign hipertermia, anemia, cranial nerves damages (facial asymmetry, palpebral ptosis), hemiparesis, intraventricular bleeding.

Conclusions: The morbidity was common in boys, average age was 2-5 and 11-17 years old. Chidrenswere operated in two ways. There were complications since intraoperatory and postoperatory period.

Key-words: tumor, obstructive hydrocephalus, morbidity structure, complications

\section{Rezumat. Managementul copiilor cu tumori intracerebrale.}

Fundal: Tumorile intracerebrale - reprezintă o nosologie gravă, cu incidență înaltă în rândul copiilor și, deseori, clinica este determinată de apariţia hidrocefaliei, cu stoparea pasajului lichidului cefalorahidian de la nivelul formării acestuia până în spațiul subarahnoidian. Rezultatele tratamentului tumorilor sistemului nervos central la copiii au fost obiectul cercetărilor încă din 1970. Multe studii au demonstrat că copiii tratați pentru tumorile cerebrale prin intervenție chirurgicală și radioterapie au dezvoltat tulburări cognitiv-intelectuale, cu evoluție progresivă cel puțin într-un un deceniu. Au fost identificaţi factori de risc pentru deteriorarea cognitivă și includ: complicaţii perioperatorii, hidrocefalia, doză mare de radiații, radiații de volum mare, chimioterapia (în special metotrexatul), vasculopatia și vârsta fragedă la momentul tratamentului.

Materiale și metode: Pentru acest studiu retrospectiv s-au folosit datele din fișele medicale ale pacienților care au beneficiat de tratament chirurgical pentru tumori Intracerebrale și Hidrocefalie Obstructivă pe perioada 2018-2019, în cadrul Spitalului Clinic Municipal de Copii „V. Ignatenco” din Chișinău, Republica Moldova, care va determina structura morbidității la copii cu tumori benigne și maligne.

Rezultate: Structura morbidității prin tumori ale sistemului nervos central la copii a fost repartizată în felul următor: 0-1 ani (1 copil - 0,76\%), 2-5 ani (5 copii - 38,46\%), 6-10 ani (2 copii - 15,38\%), 11-17 ani (5 copii - 38,46\%). Din toți 13 copii, 2 copii au fost inoperabili. Repartizarea după sexul copilului a înregistrat următoarea structură, 10 băieței $(76,92 \%)$ și 3 fete $(23,07)$.

Concluzii: Tumorile sistemului nervos central au o prevalență la genul masculin și cu vârsta medie 1-5 ani și 10-17 ani. Toți copiii cu tumori și hidrocefalie obstructivă au beneficiat de tratament în două etape: ca primă etapă se rezolvă hidrocefalia obstructivă prin ventriculocisternostomie endoscopică, ulterior după câteva zile se efectuează ablația tumorii. Complicații intra și postoperatorii au fost: anemie, hipertermie malignă, pareza nervilor cranieni(asimetrie facială, ptoză palpebrală), hemipareză, hemoragie intraoperatorie.

Cuvinte-cheie: tumoră, hidrocefalie obstructivă, tratament pe etape, structura morbidităţii.

\section{Резюме. Оценка хирургического лечения детей с внутричерепными опухолями .}

Актуальность темы: Внутричерепные опухоли - представляют собой серьезную нозологию, с высокой заболеваемостью среди детей. Клиника обусловлена появлением гидроцефалии, останавливающей прохождение спинномозговой жидкости от ее образования в субарахноидальное пространство. Результаты лечения опухолей центральной нервной системы у детей являются предметом исследований с 1970 года. Многие исследования показали, что у детей, в послеоперативном периоде развиваются когнитивно-интеллектуальные расстройства, которые прогрессируют не менее десяти лет. Факторы риска когнитивных нарушений были идентифицированы и включают: периоперационные осложнения, гидроцефалию, высокую дозу облучения, высокую дозу облучения, химиотерапию (особенно метотрексат), васкулопатию и ранний возраст начала лечения.

Материалы и методы: Для этого ретроспективного исследования использовались данные из медицинских карт пациентов, которые прошли хирургическое лечение по поводу внутричерепных опухолей в течение 20182019 в городской детской клинической больнице имени «В. Игнатенко» в Кишиневе, Республика Молдова. Полученные результаты определяют структуру заболеваемости детей с доброкачественными и злокачественными новообразованиями.

Результаты. Средний возраст был определён с помощи скрининга: в раннем возрасте $0-1$ лет было (1 ребенок - 0,76\%), 2-5 лет (5 детей - 38,46\%), 6-10 лет (2 детей - 15,38\%), 11-17 лет (5 детей - 38,46\%). Из всех 13 детей, двое были неоперабельными. Распределение ребенка по полу зарегистрировало следующую структуру: 10 мальчиков $(76,92 \%)$ и 3 девочки $(23,07 \%)$.

Выводы. Опухоли центральной нервной системы чаще встречаются у мальчиков, их средний возраст составляет 1-5 лет и 10-17 лет. Всем детям с опухолями и обструктивной гидроцефалией лечение проводилось в два этапа: первый этап был выполнен эндоскопически, затем через несколько дней удаляется опухоль. Интраоперационные и послеоперационные осложнения: анемия, злокачественная гипертермия, парез центральных нервов (асимметрия лица, птоз век), гемипарез, интраоперационное кровотечение.

Ключевые слова: опухоль, обструктивная гидроцефалия, этапное лечение, структура заболеваемости. 
Introducere. Hidrocefalia obstructivă în cadrul tumorilor cerebrale reprezintă una din cele mai complexe nozologii, determinată de prezența a două patologii concomitente, care necesită a fi abordate individual, astfel ca rezultatul actului chirurgical să fie direct proporțional cu beneficiul pacientului.

Fiind ținta cercetărilor de către medicii medievali Hippocrates, Galen, Avicenna, Hammurabi, Aristotel începând cu anii 1930, având drept sursă, celebrele papirusuri medicale, sensul patofiziologic al hidrocefaliei, acumularea anormală a lichidului în structurile cerebrale, a fost propagat științei actuale. Datele statistice actuale stabilesc, la un nivel destul de performant, mecanismele producerii hidrocefaliei. Progresul tehnico-științific a făcut posibilă determinarea diagnosticului corect şi a cauzelor instalării hidrocefaliei, însă metodele actuale de tratament rămân a fi paleative. Tumorile intracerebrale asociate de hidrocefalie obstructivă, sunt entităţi nozologice cu o pondere înaltă la copii. Cele mai frecvente cauze, care au ca rezultat dereglarea pasajului lichidului cefalorahidian, sunt reprezentate de prezenţa tumorilor intracerebrale. Structura proporțională a acestor indicatori la copii în Republica Moldova necesită a fi stabilită, fiind o sursă importantă pentru viitoarele cercetări științifice. Obstrucția căilor de circulaţie a lichidului cerebrospinal la copii apare cel mai frecvent la nivelul ventriculelor sau a canalelor de comunicație înguste, ce conectează cei patru ventriculi între ei, fie în oricare loc de unde LCR părăseşte ventriculul IV şi trece în spaţiul subarahnoidian. Datorită structurii sale fiziologice, apeductul Sylvius este vulnerabil la blocaje. Tratamentul atât al tumorii, cât şi al hidrocefaliei obstructive pune în faţa neurochirurgului opţiuni greu de realizat, de aceea este necesară evaluarea, pe perioada postoperatorie îndelungată, a metodelor de tratament aplicate acestor copii, pentru stabilirea metodei raționale şi sigure, care ar da minimum de complicaţii, dar mai ales ar perturba calitatea vieţii.

Tumorile intracraniene pot proveni, teoretic, din orice structură: creier, meninge, glanda hipofizară, craniu, eventual ţesut embrionar rezidual. Majoritatea tumorilor intracerebrale la copii sunt situate intraventricular, la nivelul fosei posterioare și sunt asociate de o hidrocefalie secundară, obstructivă [5-8, 30]. La baza acestei afirmații stă un principiu patofiziologic de amplasare predominantă a tumorilor intracerebrale la copii, care nu este cunoscut. Conform literaturii de specialitate, incidența majoră la copii o reprezintă tumorile de fosă posterioară (aproape jumătate din toate tumorile), tumorile ventriculare, tumorile pineale și chisturile agresive intracerebrale [9-12], 80\% fiind localizate intrace- rebral (dintre acestea, 50-60\% sunt glioame difuze) şi 20\% la nivelul măduvei. În Moldova, în structura cauzelor mortalităţii prin tumori maligne la populația minorilor, locul I îl ocupă tumorile organelor hemopoetice şi sistemului limfoid $(53,5 \%)$, apoi tumorile creierului şi oaselor $(14,0 \%)$, neuroblastome $(7,4-8,0 \%)$ [30]. Incidenţa este de 4-5 cazuri/100 000 locuitori/an), Incidența totală anuală a neoplasmelor cerebrale primare este de 9,5 cazuri/ 100000 de locuitori [30]. De asemenea hidrocefalia e determinată de producerea excesivă a lichidului cefalorahidian (obstrucție relativă) în cadrul papiloamelor de plex coroidian, hipertrofia vilozităților.

Odată cu creșterea morbidității și a numărului de persoane cu dizabilități neurologice, neurochirurgii din întreaga lume acordă o mare atenție tumorilor intracerebrale şi hidrocefaliei obstructive, în special sunt axaţi pe metodele noi de diagnostic şi tratament: folosirea laserului, ghidajului sonografic, monitoring-ul intraoperator. Rezultatele intervențiilor chirurgicale pentru hidrocefalia obstructivă, secundară tumorilor intracerebrale la copii în Republica Moldova, nu sunt suficient studiate, de aceea actualitatea acestei teme este pe deplin justificată.

Tratamentul chirurgical al hidrocefaliei obstructive presupune redirecționarea lichidului cefalorahidian din cavitățile ventriculare în spațiul extracerebral și ablaţia procesului tumoral. Consecutivitatea raţională a acestor etape importante este neelucidată ştiinţific. Intervențiile chirurgicale sunt considerate universale, dar gradul de eficacitate terapeutică nu este stabilit. În literatura internaţională în ultimii 2 ani s-au stabilit complicații postoperatorii determinate de tratamentul hidrocefaliei ca: migrarea toracică [11], formarea hydrotoracelui [14], tromboza venoasă cerebrală [19], chist abdominal [16], perforarea capătului distal al șuntului și meningita [18], metastazare a unei tumori de ventricul III (teratom) în cavitatea peritoneală [17] și migrare a capătului distal în cord [14]. În Republica Moldova s-au determinat complicații mecanice (infecția, obstrucția sau ruperea șuntului), dar și ca rezultat al alegerii tacticii de tratament [1].

În prezent, în literatura noastră de specialitate lipsesc studii științifice, care ar reflecta rezultatele tratamentului chirurgical şi prognosticul copiilor $\mathrm{cu}$ tumori intracerebrale asociate de hidrocefalie obstructivă.

Odată cu dezvoltarea neuroimagisticii şi metodelor de investigații performante, a crescut numărul de copii diagnosticați cu tumori intracerebrale. Astfel, la momentul actual este posibil de determinat substratul histologic al procesului tumoral prin 
metodele imunohistochimice. Tactica de tratament: prelevarea materialului biologic pentru examenul imunohistochimic sau ablația totală a tumorii este determinată de caracterul tumorii. Alteori, derivarea lichidului cefalorahidian ar fi o metodă paliativă pentru ameliorarea suferinței cerebrale şi calității vieţii copilului.

Deși s-au efectuat multiple realizări pe plan internațional [6-9] și naţional $[1,2]$ în scopul determinării mecanismelor etiopatogenetice și stabilirii unui tratament corect, complicațiile ce duc la apariția deficitelor neurologice majore și la invalidizări de grad înalt, sunt frecvente. La rezolvarea cazului este necesară participarea unui grup multidisciplinar, alcătuit din pediatru, oncolog, imagist, neurochirurg, neurolog, psiholog. Scopul tuturor neurochirurgilor, în aplicarea tratamentului chirurgical copiilor cu tumori intracerebrale și hidrocefalie obstructivă, este prelungirea perioadei de supraviețuire și ușurarea suferinței copilului $[3,4]$. Strategia chirurgicală pentru tratamentul acestor nozologii, dar şi rezultatele tratamentului efectuat, până în prezent rămâne nedeterminat și controversat $[3,14]$. Evaluarea hidrocefaliei, secundare tumorilor intracerebrale, în

Repartizarea pe sex

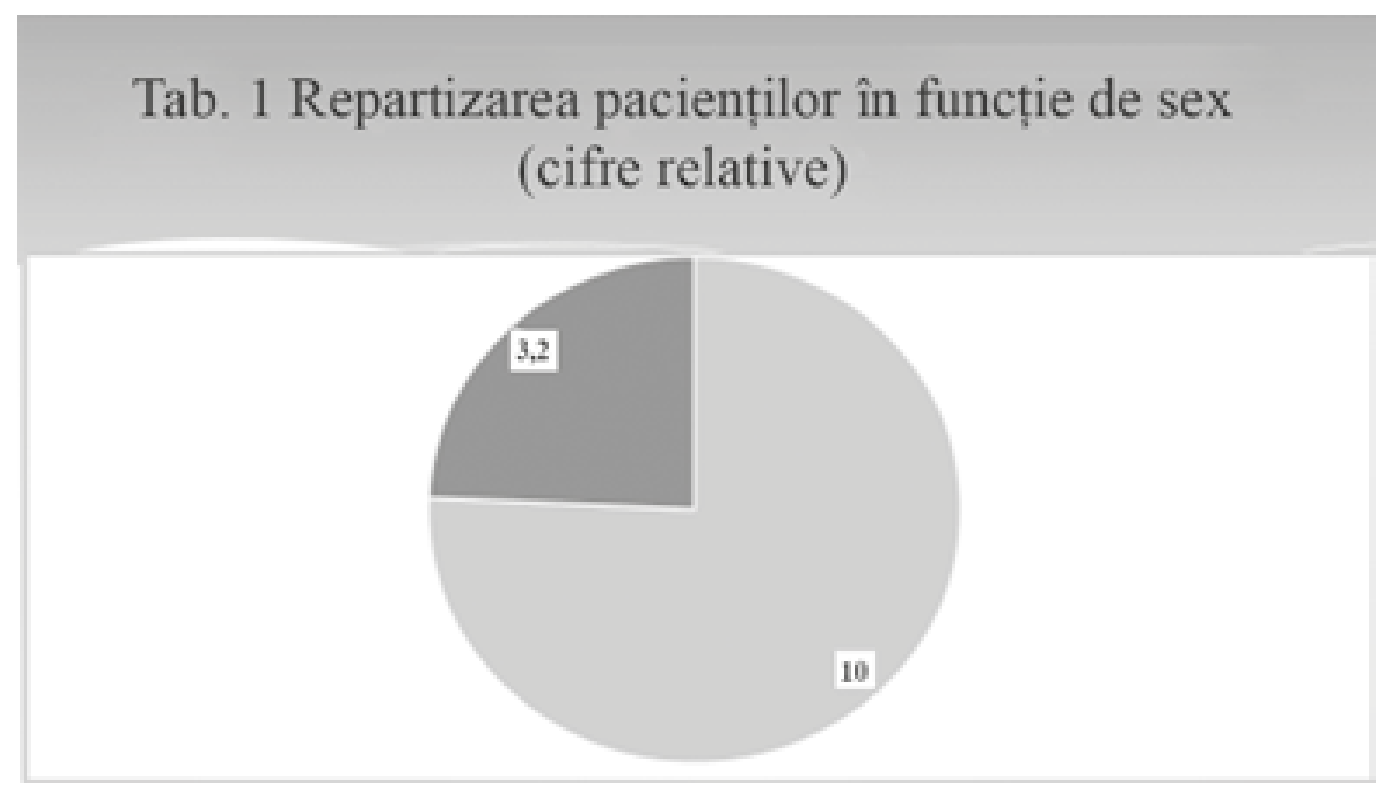

Repartizarea pe grupe de vârste

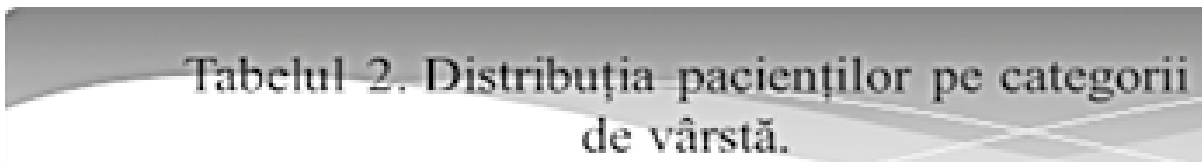

\begin{tabular}{|c|c|c|c|}
\hline Nr. categorici & $\begin{array}{c}\text { Categoria de } \\
\text { vârstă }\end{array}$ & $\begin{array}{c}\text { Numărul } \\
\text { absolut }\end{array}$ & $\begin{array}{c}\text { Număr } \\
\text { relativ }\end{array}$ \\
\hline 1 & $0-1$ & 1 & $0,76 \%$ \\
\hline 2 & $2-5$ & 5 & $38,46 \%$ \\
\hline 3 & $6-10$ & 2 & $15,38 \%$ \\
\hline 4 & $10-17$ & 5 & $38,46 \%$ \\
\hline
\end{tabular}


Domeniul geografic

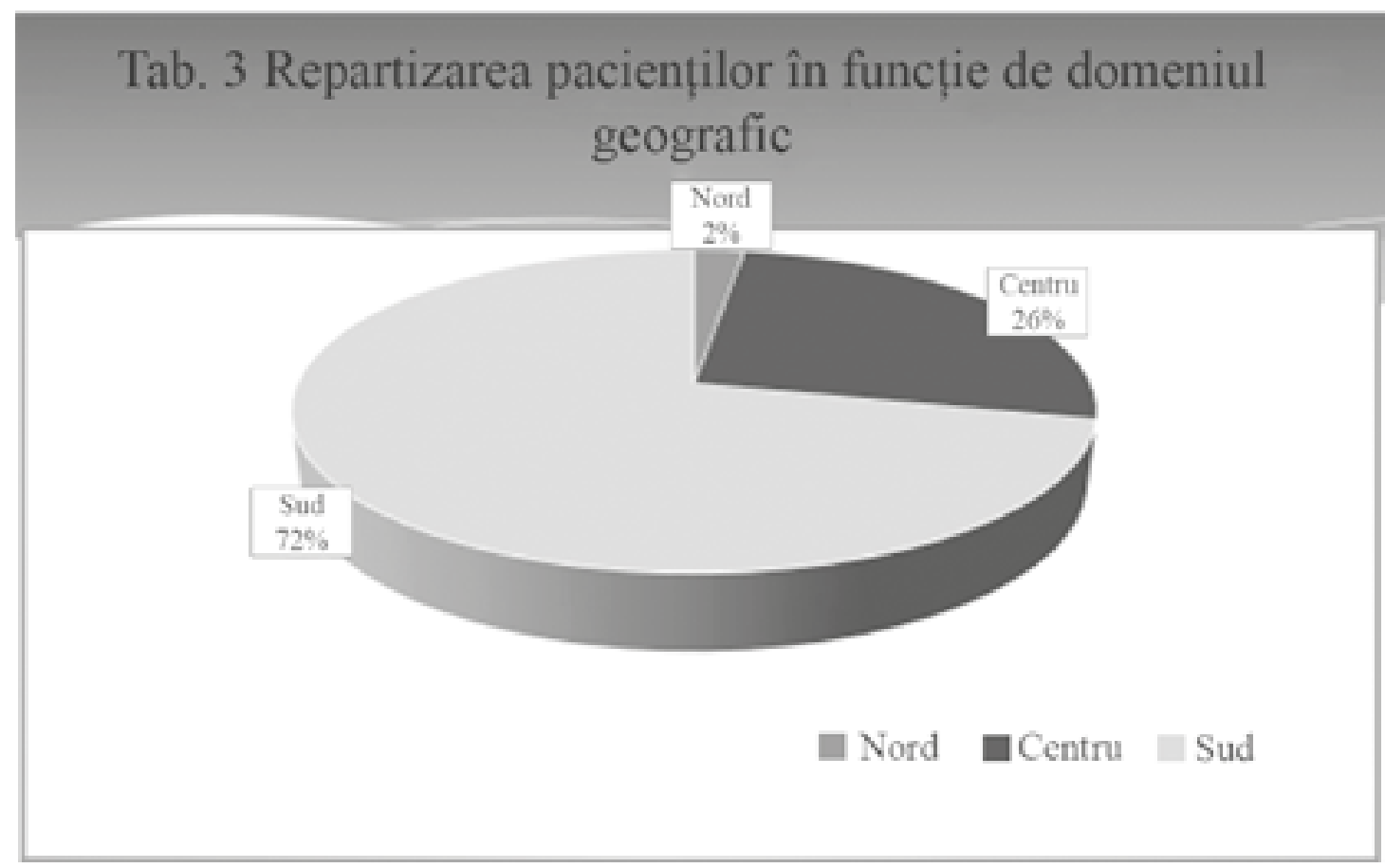

perioada pre şi postoperatorie, asupra indicatorilor de supravieţuire la copii, serveşte temei de cercetare.

Scopul studiului. Scopul cercetării este analiza clinică retrospectivă a copiilor interveniţi chirurgical pentru tumori intracerebrale şi formularea algoritmului adaptat de tratament chirurgical.

Obiectivele studiului:

Stabilirea diagnosticului copiilor cu tumori intracerebrale în baza manifestărilor clinice specifice şi rezultatelor investigaţiilor instrumentale.

Elaborarea unui algoritm de tratament chirurgical în dependenţă de rezultatele investigaţiilor imagistice (localizarea tumorii, gradul de infiltrare a structurilor de importanţă vitală, prezența hidrocefaliei).

Materiale și metode. Fișele medicale de staționar au servit ca surse pentru cercetare. Au fost incluși în studiu copiii cuprinși între vârstele 0-17 ani, care au suportat tratament chirurgical pentru tumori ale sistemului nervos central pe perioada 2018-2019.

Rezultate. Structura pacienților incluși în studiu au constituit: în total au fost tratați chirurgical 13 copii. Copiii au fost repartizați după următoarele criterii:

\section{Bibliografie} 2007

1. Revista română de pediatrie - vol. LVI, nr. 4, an.

2. Blaney S.M., Larry E.K., Hunter J. et al - Tumors of the central nervous system. In: Pizzo P A, Poplack DG (eds) Principles and practice of Pediatric Oncology (5 thedn) Philadelphia, PA: JB Lippincott, 786- 864, 2006.
- Sexul copilului (Tab. 1);

- Perioadele de vârstă (Tab. 2);

- Domeniul geografic (Tab. 3).

\section{Concluzii}

Numărul copiilor diagnosticați cu tumori ale sistemului nervos central este în creștere, luând în considerație numărul total pentru anul 2017 (9 copii).

Intervențiile chirurgicale sunt considerate universale, dar gradul de efectivitate terapeutică şi complicațiile apărute sunt motivate de mai mulți factori: internarea tardivă a pacienților în staţionarul cu profil specializat, alegerea timpului optim a volumului de intervenție, volumul rezecției tumorale, dar şi de particularitățile histologice ale tumorii, prezența hidrocefaliei şi a epilepsiei.

Neoplaziile cerebrale la copii reprezintă un factor prognostic important, aşa cum majoritatea tumorilor cerebrale diseminează pe căile lichidiene.

Copiii cu tumorile intracerebrale necesită a fi dispensarizați pe o perioadă îndelungată de timp.

3. Cohen M.E., Duffner P.K. (eds) - Brain Tumors in Children. Principles of Diagnosis and Treatment $\left(2^{\text {nd }}\right.$ edn) New York: Raven Press, 1994, 127-46,177-201, 21939, 445-481

4. Dufner PK, Korowitz ME, Krischer JP et al. The treatment of malignant brain tumors in infants and 
very young children: an update of the Pediatric Oncology Group experience. Neurooncology, 1999, 1, 152-161.

5. Freemen C.R., Taylor R.E., Kortmann R.D., Carrie C. - Radiotherapy for medulloblastoma in children: a perspective on current international clinical research efforts. Med Pedatr. Oncol, 2002, 39, 99-108

6. Gotzer M.A., Janss A.J., Fung K.M. et al - TrkC expression predicts good clinical outcome in primitive neuroectodermal brain tumors. J Clin Oncol, 2000, 18, 1027-1035.

7. Herms J., Neidt I., Luscher B. et al - c-myc expression in meduloblastoma and his prognostic value. Int $\mathrm{J}$ Cancer, 2000, 395-402

8. Pomeroy S.L., Tamayo P., Gaasenbeck M. et al. - Prediction of central nervous system embrional tumor outcome based on gene expression. Nature, 2002, 415, 436-442

9. Heckl, Aschoff A., Kunze S. - Radiation-induced cavernous hemangiomas of the brain: a late effect predominantly in children. Cancer, 2002, 94, 3285-3291.

10. Kleihues P., Cavenee W.K. (eds) - Pathology and genetics of tumors of the Nervous System. Lyon: IARC (2000).

11. Ko J.K., Cha S.H., Choi B.K., Lee J.I., Yun E.Y., Choi C.H. „Hemorrhage Rates Associated with Two Methods of Ventriculostomy: External Ventricular Drainage vs Ventriculoperitoneal shunt procedure". Neurol Med Chir (Tokyo).2014 Feb10.

12. Lo W.B., Ramirez R., Rodrigues D., Solanki G.A. „,Ventriculoperitoneal shunt disconnection associated with spontaneous knot formation in the peritoneal catheter". BMJ Case Rep. 2013 May

13. Kortmann R.D., Kuhl J., Timmermann B. et al. Current and futures strategies in interdisciplinary treatment of medulloblastoma, supratentorial PNET (primitive neuroectoderman tumors) and intracranial germ cell tumors in childhood. Strahlenther Onkol, 2001, 177, 447-461.

14. Mandiwanza T., Kaliaperumal C., Caird J. „, Central brain herniation in shunted Dandy Walker cyst". Childs Nerv Syst. 2013 Jun;
15. Mattei T.A., Salma A., Lin J.J. ,,Spontaneous bowel perforation from distal catheter leading to meningitis: a rare but frequently overlooked complication of ventriculoperitoneal shunts". Pediatr Neurol. 2013 Jun

16. Matsubara T., Ayuzawa S., Aoki T., Ikeda G., Shiigai M., Matsumura A. Neurol Med Chir (Tokyo). „Cerebral venous thrombosis after ventriculoperitoneal shunting: a case report". Neurol Med Chir (Tokyo). 2013 Nov 20.

17. Meier U., Stengel D., Müller C., Fritsch M.J., Kehler U., Langer N., Kiefer M., Eymann R., Schuhmann M.U., Speil A., Weber F., Remenez V., Rohde V,. Ludwig H.C., Lemcke ,, Predictors of subsequent overdrainage and clinical outcomes after ventriculoperitoneal shunting for idiopathic normal pressure hydrocephalus. J. Neurosurgery. 2013 Dec;73(6): 1054-1060.

18. Michaelis J., Kaletsch U., Kaatsch P. - Epidemiology of childhood brain tumour. ZentralblNeurochir, 2000, 61, 80-87.

19. Mulhern R.K., Reddick W.E., Palmer S.L. et al. Neurocognitive deficits in medulloblastoma survivors and white matter loss. Ann Neurol, 1999, 46, 834-841.

20. Radcliffe J., Bunin G.R., Sutton L.N. et al. - Cognitive deficits in long term survivors of childhood medulloblastoma and other non-cortical tumors: age dependent effects of whole brain irradiation. Int J Dev Neurosci, 1994, $12,327-334$

21. Siffert J., Allen J.K. - Late effects of therapy of thalamic and hypothalamic tumors in childhood: vascular, neurobehavioural and neoplastic. Pediatr. Neurosurg, 2000, 33, 105-111.

22. Гогорян С. Ф. и др. Опухоли головного мозга, сочетаюшиеся с гидроиефалией. В: Журнал Вопросы нейрохирургии им. Н.Н. Бурденко, 2008, № 4, с. 39-42.

23. Wikipedia search.

\title{
ROLUL CHIRURGIEI MINIINVAZIVE ÎN TRATAMENTUL CANCERULUI TIROIDIAN INCIPIENT
}

\author{
Andrei ȚîBîRNĂ, dr. șt. med., conf. univ., Gheorghe CIGOREANU
}

Universitatea de Medicină și Farmacie „N. Testemițanu”

e-mail: andrei.tibirna@usmf.md

\begin{abstract}
Rezumat.
Chirurgia miniinvazivă tiroidiană este o ramură relativ nouă care a început să se dezvolte începând cu anii 90 ai secolului trecut, ea vine ca un răspuns la o creștere a incidenței tumorilor tiroidiene ca cancere și adenoame în ultimele decenii. Chirurgia miniinvazivă tiroidiană are 2 direcții principale: cu și fără abord în regiunea gâtului, iar cele cu abord la nivelul gâtului se împart în endoscopice și non endoscopice. Intervențiile mininvazive au o serie de avantaje faţă de cele clasice ca reducere a sindromului algic postoperator și respectiv a consumului de analgezice, timpul de staționare scăzut și rezultate cosmetice mult mai bune. Nu toți pacienții cu tumori tiroidiene pot fi operați miniinvaziv, există o serie de criterii de selecție: stadiul incipient al cancerului tiroidian primar sau adenoame mai mici de 3,5 cm în diametru, fără
\end{abstract}

